\title{
EFFECTIVENESS OF BENZOCAINE GELPATCH IN REDUCING PALATAL INJECTION PAIN IN PEDIATRIC DENTAL PATIENTS: A SPLIT-MOUTH RANDOMIZED CLINICAL TRIAL
}

\author{
Huda A. Osman ${ }^{1}$ BDs, Amina M. Abdelrahman2 PhD, Aly A. Sharaf2 PhD. \\ ABSTRACT
}

INTRODUCTION: There is an urgent need to develop and improve techniques that decrease pain in the dental visit especially during injections. Topical anesthesia was found to be one of the most effective methods to control pain associated with injections in children.

OBJECTIVES: we aimed in this study to evaluate the effectiveness of gel patch form of benzocaine anesthetic in comparison to oral benzocaine gel applied before palatal injection in children in reducing the pain associated with injection procedure.

MATERIALS AND METHODS: A randomized split-mouth clinical trial was carried out with a sample of 32 children ranging in age between 6 and 8 years old that met the inclusion criteria. Each participant attended two visits to receive both forms of topical anesthetics and the outcome was measured using Face Pain Scale- Revised (FPS-R) and Sound Eye Motor (SEM) scales.

RESULTS: A high statistically significant difference was found between the two forms of benzocaine in reducing pain. Both FPS- R and SEM scales gave lower scores when BZC gel patch was applied with $\mathrm{P}=.0001$ and $\mathrm{P}=.001$ respectively.

CONCLUSION: Benzocaine gel patch form has a superior effect in reducing pain associated with palatal injection in children.

KEY WORDS: Benzocaine, Topical, oral patch, pain, dental anesthesia, children.

RUNNING TITLE: Using Anesthetic Gel Patches to Reduce Pain of Palatal Injection.

1. Bachelor of Dentistry, Faculty of Dentistry, Alexandria University, Alexandria, Egypt.

2. Professor of Pediatric Dentistry, Department of Pediatric Dentistry and Dental Public Health, Faculty of Dentistry, Alexandria University, Alexandria, Egypt

\section{* Corresponding author:}

E-mail:huda85dent@gmail.com

\section{INTRODUCTION}

Young children's response to dental treatment can greatly affect the course and quality of dental services provided and can give a future prediction about attitudes toward dental care (1). Therefore, behavior guidance techniques in pediatric dentistry are a corner stone for control and success of any dental intervention (2).

Fear of pain related behaviors is the most difficult aspect of children management in dental office (3). Mota- Veloso et al in 2016,(4) found that most children postpone their dental visits because of fear of pain and injections which can negatively influence the patient's oral health and quality of life. Murthy AK in 2014,(5) found that children with high dental fear had about two folds higher risk to caries compared to children with low fear. Therefore, there is an urgent need to improve techniques that decrease pain in the dental visit specially during injections.

Local anesthetic administration is the backbone method to control pain. It is a prerequisite before dental procedures in children (6). Effective anesthesia provides a relaxed cooperative patient, effective work with good quality results and satisfied parents. Poor child compliance during the beginning of anesthetic technique because of "fear of needle prick" is a common problem $(7,8)$. Topical anesthesia was found to be the most effective and practical method used to control pain and anxiety associated with injections in children. It utilizes both psychological and pharmacological sides of management (9). Studies found that topical agents' effectiveness may vary as a result of differences in chemical composition, vehicle formulations or pharmaceutical forms and physical methods of application $(8,10,11)$. Several improvements have become available for use in the dental field specially for children (12). Thus, changing the pharmaceutical form or device carrying the drug to gain more effectiveness is an interesting method to improve the use of topical anesthetic agents (13). The most common form used in dentistry is the topical oral gel. Sometimes it cannot be effective in reducing pain during dental injections due to its lack of bioadhesiveness to oral mucosa and easy dilution by oral fluids resulting in unpleasant taste (14). These problems could be reduced by using more stable mucoadhesive systems as patches $(15,16)$.

Benzocaine is one of the most common agents that are widely used as topical anesthetic. It has faster onset, low toxicity and potent topical anesthetic effects (17-20). Topicale $^{\mathrm{TM}}$ gel patch is a benzocaine gel patches that has been introduced and approved to be used in dental practice. These gel patches give Benzocaine the advantages of being mucoadhesive beside its rapid onset of anesthesia. Its advantages that have been claimed by the manufacturer make it an interesting product for studying and evaluation. In the light of previous literature, the positive feedback of majority of the studies toward mucoadhesive patches use in dentistry in general, makes studying of this new form of 
patches interesting (21-25). In this study, we aimed to evaluate the effectiveness of anesthetic benzocaine oral gel patches in comparison to ordinary benzocaine oral gels by measuring the reduction of pain degree associated with palatal injection in pediatric dental patients using valid study design and objective and subjective measuring scales.

The null hypothesis tested was that there will be no difference between both forms of topical benzocaine anesthetic in reducing pain scores during palatal injections in children.

\section{MATERIALS AND METHODS}

The approval of Research Ethics Committee in the Faculty of Dentistry, Alexandria University, was first secured before the beginning of the study (IRB 00010556) - (IORG 0008839). The study also was registered on the ClinicalTrials.gov public website (NCT04317508). Informed consents were secured from all parents/ guardians after full explanation of the objectives of the study, risks and benefits and signing the informed written consent by the parents.

Study design: The study was a randomized controlled clinical trial with a split mouth design.

\section{Participants:}

Eligibility Criteria: The participants enrolled in this study were healthy children ranging in age from 6 to 8 years with a cooperative behavior according to Frankl's scale scores 3 or 4 without previous negative dental experience. They needed dental interventions on both sides in the maxillary arch that required palatal injection.

Exclusion criteria: Uncooperative children or with intellectual or physical disabilities or medical condition. Children with acute pain, emergency visits or received pre medications or analgesics 48 hours before testing were also excluded.

Study Setting: The sample was collected from children attending the clinic of Department of Pediatric Dentistry Alexandria University.

\section{Intervention:}

Following case history and clinical examination, the procedure was explained to the child and parents in a simple terminology. A brief explanation was given to the child about FPS-R, after which the child was asked to choose the face that best described his/ her feelings. This step was performed to determine baseline comfort before applying the topical anesthetic to ensure the absence of any discomfort. If present, verbal communication was done. In order to avoid anxiety, no mention of any anticipated or expected pain during explanation of the scale or before the procedure was done (26).

The patient was positioned in a supine position parallel to the floor. After isolating with cotton rolls and suction, the injection site was dried using 2" $\times 2$ " sterile gauze. Suction was used to avoid quick dissolution of the topical agent. Topical anesthetic that was randomly assigned to the case was applied on the area of palatal injection for 30 seconds. The local anesthetic then was deposited slowly in constant rate $(1 \mathrm{ml} / \mathrm{min})$ using a 27 " gauge needle. The procedure of injection was documented by video recording that recorded the eye, body movement and the voice of the child (27).
After delivery of palatal injection, the FPS-R scale was scored by the child.

Once the required data was collected, the same topical anesthetic form was applied at the site of buccal infiltration for 30 seconds then buccal injection was carried on to avoid bias in results.

The maximum anesthetic doses allowed for both topical and local anesthetics used were calculated according to the child's weight. As the gel patch can be easily cut into sections and modified to desired shape and thickness, the benzocaine dosage control was feasible.

At least one-week interval was secured between the two visits and the same steps were performed using the other alternate of the topical anesthesia (28).

\section{Materials:}

- Topicale ${ }^{\circledR}$ 18\% benzocaine topical anesthetic gel patch (Premier Dental Products, Inc., Plymouth Meeting, Pennsylvania, United States)

- Opahl® 20\% benzocaine topical anesthetic gel (Dharma research,Inc,Miami, Flourida)

- Local anesthetic: Lidocaine HCL 2\% with Epinephrine 1:100,000 solution (Octacaine 100, Novocol Pharmaceutical of Canada, Inc.)

Outcomes:

Two scales were used to assess pain outcome:

A. Faces pain scale - Revised (FPS- R):

A subjective scale to assess pain perception where each child was shown a set of six cartoon faces with varying facial expressions representing ascending degrees of pain(Figure 1) (21). The faces started by a neutral face with no facial signs of pain or discomfort (score 0) and ended by extremely painful expression (score 10). The child chooses a face that represents his/ her degree of pain experienced during the injection (29).

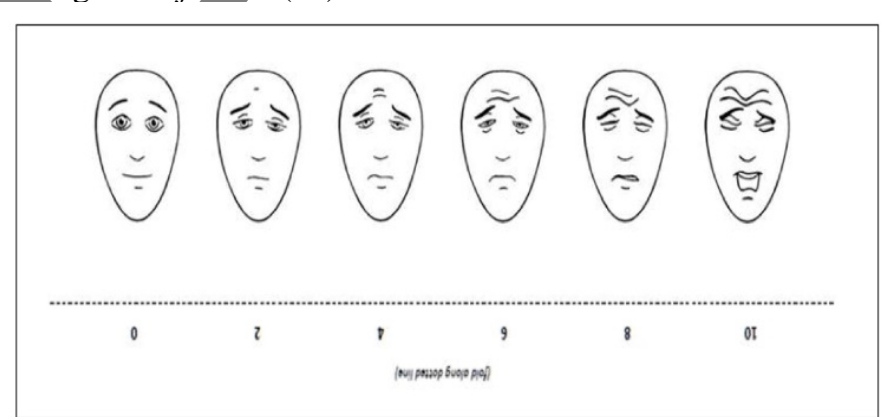

Figure 1: Faces of Pain Scale- Revised (FPS-R)

B. The Sound, Eye, Motor (SEM) Scale:

A scale used to measure pain or comfort, taking into account SEM components of the child's response to stimulation (Table 1) (30). An independent investigator was trained on measuring and calibrating of the SEM scale through video recording to the procedure and was blinded from the technique used during topical anesthesia. The score in each category of the scale ranges from 1 (no physical reaction to pain) to 4 (intense reaction to pain). The SEM score was determined by summing the grade values. The lower scores represent a less physical reaction to pain during the procedure of injection than does a higher score. 
Table 1: Components of SEM scale

\begin{tabular}{|l|l|l|l|l}
\hline Parameter & \multicolumn{1}{|c|}{ Comfort } & \multicolumn{1}{|c|}{ Mild discomfort } & Moderate discomfort & Severe discomfort \\
\hline Grade & 1 & 2 & 3 & 4 \\
\hline Sound & No sound & Non-specific sound & $\begin{array}{l}\text { Verbal compliant, } \\
\text { louder sound }\end{array}$ & $\begin{array}{l}\text { Verbal compliant } \\
\text { shouting, crying }\end{array}$ \\
\hline Eye & No signs & $\begin{array}{l}\text { Dilated eye without } \\
\text { tears }\end{array}$ & $\begin{array}{l}\text { Tears, sudden eye } \\
\text { movement }\end{array}$ & $\begin{array}{l}\text { Crying, tears all over } \\
\text { face }\end{array}$ \\
\hline Motor & $\begin{array}{l}\text { Relaxed body } \\
\text { And hand }\end{array}$ & $\begin{array}{l}\text { Muscular contractions } \\
\text { of hand }\end{array}$ & $\begin{array}{l}\text { Sudden body and } \\
\text { hand Movements }\end{array}$ & $\begin{array}{l}\text { Hand movement for } \\
\text { defense, } \\
\text { Turning the head to } \\
\text { opposite side }\end{array}$ \\
\hline
\end{tabular}

Sample Size Estimation: Thirty participants were the minimally required sample size for this study. The sample was calculated By using Repeated Measures ANOVA Power Analysis in NCSS\&PASS program, minimum sample of 30 Patients achieve $80 \%$ power to detect difference of (1.2) in the effectiveness of the two forms of oral topical anesthetic Topicale ${ }^{\mathrm{TM}}$ gel patch (Benzocaine 18\%) and Benzocaine oral gel $20 \%$ in reducing pain and discomfort during injection of local anesthesia in pediatric dental patients with a target significance level at 5\% (14). The number of included participants was increased to 32 to control the attrition bias.

Randomization Technique: In the first visit of each subject, they were randomly assigned to receive one of the topical anesthetic forms. At the second visit, the other alternate was received. Participants were randomly assigned using a computer generated list of random numbers Allocation was performed by a trial independent individual and the allocation was in blocks to ensure that both study groups have equal number of children.

Grouping: The thirty-two children that met the inclusion criteria were scheduled to receive their needed treatment at two visits with at least one-week interval between both visits. A total of 64 dental sessions were planned for the 32 children included in the study. Participants were allocated equally into two groups:

Group I: children received local injections using Topicale ${ }^{\mathrm{TM}}$ gel patch as a topical anesthetic (intervention) $(n=32)$

Group II: children received local injections using $20 \%$ benzocaine gel as a topical anesthetic (control). $(n=32)$

Allocation Concealment: Each child included in this study was given a serial number that was used in the allocation. These numbers were written in identical sheets with the group to which each child was allocated. These sheets were placed inside opaque envelopes carrying the names of the children. Independent personnel assigned the role of keeping the envelopes and unfolding them only at the time of the procedure so that the group the child was allocated to be concealed from the investigator. Allocation was performed by an independent individual and the allocation ratio was equal

Blinding: The operator was not blinded to the type of topical anesthetic applied as each type has a different application technique. However, both the child and the independent personnel who assessed the outcome variables were blinded to the procedure's regimen. The statistician was also blinded about the treatment groups.

Statistical Analysis: Data was reviewed to check for any errors during data entry. The outcome of the FPS-R scale was coded $0,2,4,6,8,10$ coinciding with the scores of the scale. While the SEM scale records was the sum of the scores of the Sound, Eye and Motor components of the scale. Wilcoxon signed rank test was used to analyze the data. The level of statistical significance was set at 0.05 .

\section{RESULTS}

The study was carried out on 32 children with mean age (6.8 \pm .8 ) years. Seventeen children were females (53.1\%) while 15 children (46.9\%) were males. (Table 2 ).

Table 2: Demographic data of the sample

\begin{tabular}{|l|c|}
\hline Characteristics & $\begin{array}{c}\text { Study sample } \\
(\mathrm{n}=32)\end{array}$ \\
\hline Children Age (years) & $6.8 \pm .8$ \\
\hline Mean \pm SD & $6-8$ \\
\hline Range & $15(46.9 \%)$ \\
\hline Male (\%) & $17(53.1 \%)$ \\
\hline Female (\%)
\end{tabular}

During sample collection, forty-five children were examined to be included in the study. Eight participants were excluded from the sample as they showed a negative behavior either before or after the application of topical anesthetic agent and before the local anesthesia injection step in the first or second visits. Verbal communication and reassurance failed to gain their cooperation again. The injection step and required dental treatments were performed but no data were collected from those children. Five participants did not fit to the study design were excluded as four children did not attend the second visit and one child extracted the decayed tooth on the other side before the second visit. The final number of the participants was 32 children and they were included in the statistical analysis of the data. The flow chart of the study is demonstrated in figure 2.

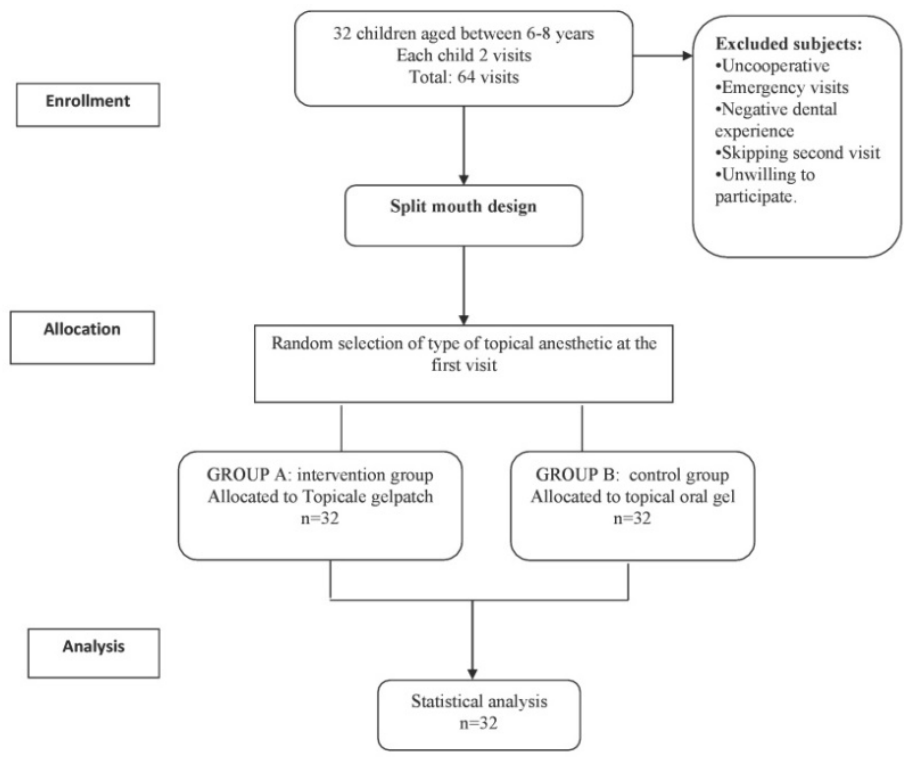

Figure 2: CONSORT Flow chart of the study. 
The statistical analysis revealed that there was highly significant difference in the effectiveness of the two forms of oral topical anesthetic: FPS- R median of pain scale was higher in Benzocaine gel than gel patch technique ( 6 vs 4 respectively $),(\mathrm{z}=-3.6, \mathrm{P}=.0001)$. The same results were obtained using Sound, eye, motor scale as $(\mathrm{z}=-3.2, \mathrm{P}=.001)$ as illustrated in table 3 and figures $\mathbf{3 , 4}$ and 5

Table 3: The effectiveness of the two forms of benzocaine in reducing injection pain using FPS-R and SEM scales.

\begin{tabular}{|l|c|c|c|}
\hline Pain scores & $\begin{array}{c}\text { Gel Patch } \\
(\mathbf{N}=\mathbf{3 2})\end{array}$ & $\begin{array}{c}\text { Benzocaine gel } \\
(\mathbf{N}=\mathbf{3 2})\end{array}$ & $\begin{array}{c}\text { Test of significance } \\
(\mathbf{p})\end{array}$ \\
\hline $\begin{array}{l}\text { FPS-R } \\
\text { Median (Min -Max) }\end{array}$ & $4(\mathbf{0 - 1 0 )}$ & $6(2-10)$ & $\left(\mathrm{z}=-3.6, \mathrm{P}=.0001^{*}\right)$ \\
\hline $\begin{array}{l}\text { SEM scale } \\
\text { Median (Min -Max) }\end{array}$ & $5(3-10)$ & $7(3-12)$ & $\left(\mathrm{z}=-3.2, \mathrm{P}=.001^{*}\right)$ \\
\hline
\end{tabular}

(FPS-R); Faces of Pain Scale- Revised

SEM; Sound, eye, motor

: Wilcoxon Signed Ranks Test

; statistical signific ance

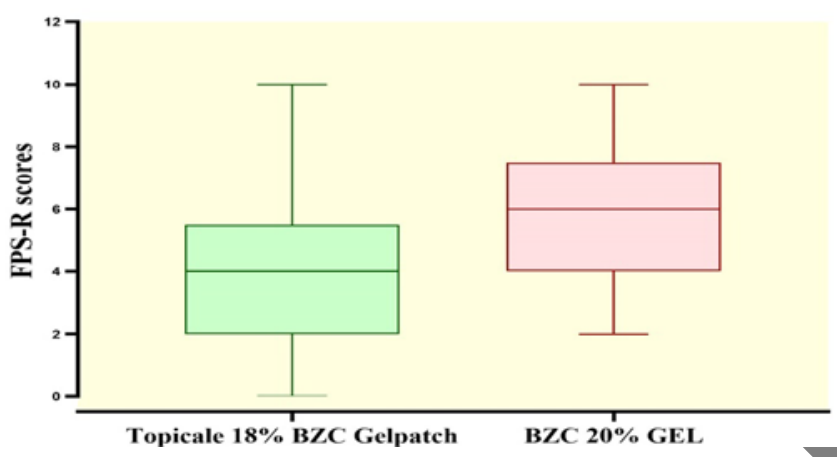

Figure 3:FPS-R scale outcome of the two forms of benzocaine topical anesthetic.

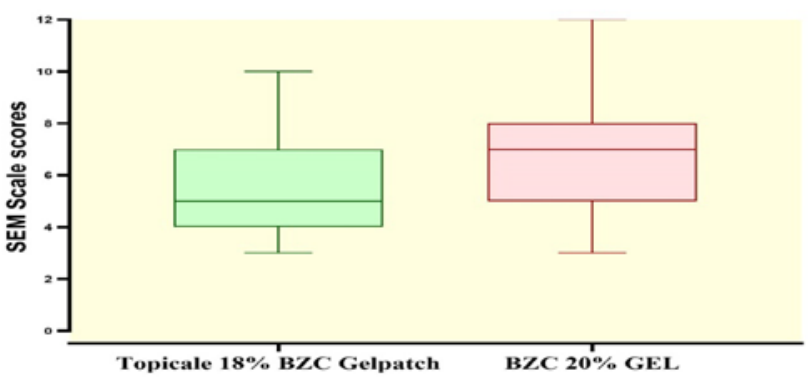

Figure 4: SEM scale outcome of the two forms of benzocaine topical anesthetic.

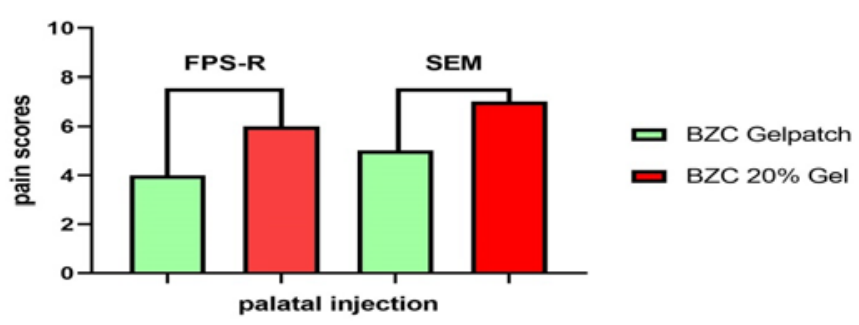

Figure 5: Bar chart demonstrating the effectiveness of both benzocaine forms in reducing pain scores in palatal injection.

Alexandria Dental Journal. Volume 46 Issue 1 Section C

\section{DISCUSSION}

Although benzocaine is one of the most commonly used agents as a topical anesthetic in dentistry, there is not enough literature comparing the efficacy of different forms of benzocaine to each other. The majority of the studies compared benzocaine to other agents or devices as a control treatment or even to a placebo $(19,20,31,32)$. Also, few studies were found testing the application of benzocaine in other formulations to improve its action (10).

Based on the obtained results, the null hypothesis that both forms of Benzocaine topical anesthetics will reduce pain scores to sinitlar levels regarding their use with palatal injections was rejected.

Benzocaine gel patch was tested on palatal injection in this study as this site of injection was perceived to be of relatively greater discomfort and is usually required during many procedures in maxillary teeth (32). Also, the effectiveness of topical anesthetics at this site is still questioned and needs further studying (33). Randomized controlled studies by Franz-Montan M et al in 2012 (34) and

de Freiras GC et al in 2015 (35) have demonstrated that topical anesthetics were unable to control the pain from anesthetic injection in the palate but only reduced the pain induced by needle insertion.

Only cooperative children were included in our study (positive or definitely positive according to Frankl behavior rating scale) to have a reliable pain assessment outcome. Children with previous painful dental experiences were excluded as negative experience can affect the degree of response to painful stimuli (11). Children who came to the clinic in need of emergency treatment were also excluded as their reaction to the painful procedures would not have been reliable. Besides, some of them were on medications or analgesics that could have affected the outcome (6).

Split mouth design was conducted in this study where the child served as his own control. This design removes a lot of inter-subject variability from the treatment outcome. It potentially requires fewer subjects than a parallel-group trial with the same power (21). The Faces of Pain Scale-Revised and Sound Eye Motor scales had proven their validity (2224). They were used in this study to give more strength to the outcome by using both subjective and objective methods to conduct the results $(29,33)$.

The materials tested in our study were $18 \%$ Benzocaine in gel patch form (Topicale ${ }^{\mathrm{TM}}$ gel patch) and $20 \%$ benzocaine oral gel as a control. The results of our study showed that Topicale ${ }^{\mathrm{TM}}$ gel patch (18\% benzocaine) exhibited a better outcome with palatal injection and reduction in pain scores to a highly statistically significant level compared to $20 \%$ benzocaine gel regarding both FPS-R and SEM scales.

In contrast to the results obtained from our study, Bagesund $M$ et al in 2008 found that there was no significant difference regarding pain rating between the patch and the gel (14). The results of that study showed that the gel was more effective than the patch in reducing the pain during palatal injections when applied for short duration (less than 15 minute). The authors referred those findings to the physical properties of the patch and the long duration needed to achieve proper surface anesthesia (15 minutes at least).

The patches used in their study were large in size with a plain firm surface that cannot be modified easily to fit over 
the wavy structure of the palatal mucosa. The gel, on the other hand, succeeded to flow and adhere better to the palatal surface details and provide better anesthetic effect (14). Benzocaine gel patches used in our study (Topicale ${ }^{\mathrm{TM}}$ gel patch) had an advantage over both ordinary gels and lidocaine patches as it is flexible and convenient to use. It can be modified, reshaped, cut into sections and adapted well to details of this wavy surface of the palatal mucosa by slight pressure during placement. Also, it dissolves and flows gradually during application and acts as a gel on the applied surface. Benzocaine gel patches could anesthetize the surface mucosa within 20 to 30 seconds according to the manufacturer. This explains the contrast in the findings between our study and the study of Bagesund $M$ et al and proved that benzocaine Topicale ${ }^{\mathrm{TM}}$ gel patch can be a useful effective alternative.

Another study by Kreider K.A. et al (36) also reported a different outcome regarding the use of patches. The study reported that there was no significant difference in reduction in pain scores regarding self-reported pain measures. But objective outcome using SEM scale showed better results and more reduction in pain scores to significant levels when the patch was used. The authors referred that to some limitations in the validity of self-reported measures used in the study (36). The same study also concluded at the end that the use of anesthetic patches is still favored and preferred by the children. Also it was associated with some objective evidence of reduced pain compared to the gel form (36).

On the other hand, in accordance with our study results, Shehab LA et al in 2015 reported a significant reduction in pain scores when the patch was used. The significance level in the results was similar to those obtained in our study (18). Our results were also supported by the findings of other studies and reviews that were concerned mainly with documenting the improvement in the effectiveness of anesthetic agents when included in mucoadhesive forms $(31,37)$. Nakamura S, et al in 2013, also studied a Benzocaine topical anesthesia included in adhesive oral patches and they were more effective in pain reduction than conventional method (20\% benzocaine gel on a cotton ball) (37). Sharifi R et al in 2017 in a systematic review and metaanalysis study concluded that benzocaine anesthetic agent included in patch can be more effective compared with nonpatch form in reducing pain associated with needle insertion in maxillary injections (31). Thus, the results of our study may confirm the hypothesis that topical anesthesia had an actual physical effect in pain reduction and not only a psychological effect.

Throughout the study, there were no adverse effects or hypersensitivity reactions noticed upon the use of benzocaine patch even with prolonged contact to the mucosa or repeated application. However, during the clinical application of the gel patch, it was found to be difficult in handling as it was sticking to the instruments and gloves and did not adhere to the mucosal surface easily in some cases. This required an extra time for application of the patch in place prior to local anesthetic administration.

It was sometimes easy to dislodge especially when the saliva contaminates the area of application or during tongue movement. In a few cases, the patch had to be held in place against the mucosa by the operator during the entire time of application.

These limitations are in accordance with the findings mentioned in the review made by Annigeri R et al in 2014 studying the oral patches limitations in general (13).

CONCLUSION: Benzocaine gel patch form has superior results in reducing pain associated with palatal injection in children.

CONFLICT OF INTEREST: The authors declare that they have no conflict of interest.

\section{ACKNOWLEDGEMENT}

The authors would like to thank Dr. Ehsan Akram Deghidy (Assistant lecturer of Biomedical Informatics and Medical Statistics Alexandria University, Alexandria, Egypt; for her help in the statistical part of this study.

\section{REFERENCES}

1. Sharma A, Rishi T. Behavior Assessment of Children in Dental Settings: A Retrospective Study. Int J Paediatr Dent . 2011;4:35-9.

2. Diercke K, Ollinger I, Bermejo J L, Stucke K. Dental Fear in Children and Adolescents: Comparison of Forms of Anxiety Management Practiced by General and Paediatric Dentists. Int J Paediatr Dent. 2012; 22: 60-7.

3. Asokan A, Rao AP, Mohan G, Reddy NV, Kumar K. A pain perception comparison of intraoral dental anesthesia with 26 and 30 gauge needles in 6-12-year-old children. J Pediatr Dent. 2014;2:56-60.

4. Mota-Veloso I, Soares ME, Alencar BM, Marques LS, Ramos-Jorge ML, Ramos-Jorge J. Impact of untreated dental caries and its clinical consequences on the oral health related quality of life of schoolchildren aged 8-10 years. Qual/Life Res. 2016:193-9. doi: 10.1007/s11136015-1059-7. Epub 2015 Jul 2.

Murthy AK, Pramila M, Ranganath S. Prevalence of clinical consequences of untreated dental caries and its relation to dental fearamong 12-15-year-old schoolchildren in Bangalore city, Indis. Eur Arch Paediatr Dent. 2014;15:45-9. doi: 10.1007/s40368-013-0064-1.

6. Armfield, JM., Ketting $\mathrm{M}$. Predictors of dental avoidance among Australian adults with different levels of dental anxiety. Health Psychol. 2015;34:929-40. doi: 10.1037/hea0000186. Epub 2014 Dec 22.

7. Schmitz AK, Vierhaus M, Lohaus A. Pain tolerance in children and adolescents: sex differences and psychosocial influences on pain threshold and endurance. Eur J Pain. 2013;17:124-31. doi: 10.1002/j.15322149.2012.00169.x. Epub 2012 Jun 19

8. Moore PA, Hersh EV. Local anesthetics: pharmacology and toxicology. Dent Clin North Am. 2010;54:587-99. doi: 10.1016/j.cden.2010.06.015.

9. Salma AN, Ramakrishnan $M$. Use of anesthesia in pediatric dentistry: A cross-sectional survey. Int J Pedod Rehabil. 2016;1:5-9.

10. Franz-Montan M, Cereda CM, Gaspari A, da Silva CM, de Araújo DR, Padula C, et al. Liposomal benzocaine gel formulation: correlation between in vitro assays and in vivo topical anesthesia in volunteers. J Liposome Res. 2013;23:54-60. doi: 10.3109/08982104.2012.742536. Epub 2012 Dec 17. 
11. El-Sekenedi M. Factors Affecting Self Reported Pain among Egyptian Children attending dental treatment facilities. “ MSc Thesis”. Alexandria, Egypt: Alexandria university.2014

12. Garret-Bernardin A, Cantile T, D'Antò V, Galanakis A, Fauxpoint G, Ferrazzano GF et al. Pain Experience and Behavior Management in Pediatric Dentistry: A Comparison between Traditional Local Anesthesia and the Wand Computerized Delivery System. Pain Res Manag. 2017;2017:7941238. doi: 10.1155/2017/7941238. Epub 2017 Feb 15.

13. Annigeri R, Jadhav M. Mucoadhesive Patch: A Novel drug delivery. J Pharm Pharm Sci. 2014;3:56-62.

14. Bagesund M, Tabrizi P. Lidocaine 20\% patch vs lidocaine $5 \%$ gel for topical anaesthesia of oral mucosa. Int. J. Paediatr. Dent. 2008;18:452-60.

15. Boyce RA, Kirpalani T, Mohan N. Updates of Topical and Local Anesthesia Agents. Dent Clin North Am. 2016;60:445-71. doi: 10.1016/j.cden.2015.12.001.

16. Lee HS. Recent advances in topical anesthesia. J Dent Anesth Pain Med. 2016;16:237-44. 10.17245/jdapm.2016.16.4.237.

17. Gondim DGA, Montagner AM, Pita-Neto IC, Bringel RJS, Sandrini FAL, Moreno EFC, et al. Comparative Analysis of the Effectiveness of the Topical Administration of Benzocaine and EMLA ${ }^{\circledR}$ on Oral Pain and Tactile Sensitivity. Int J Dent. 2018;2018:7916274. doi: 10.1155/2018/7916274.eCollection 2018.

18. Shehab LA, Basheer B, Baroudi K. Effectiveness of lidocaine Denti patch ${ }^{\circledR}$ system versus lidocaine gel as topical anesthetic agent in children. J Indian Soc Pedod Prev Dent. 2015;33:285-90.

19. Leyda A, Llena C. Comparation of the eutectic mixture of lidocaine/prilocain versus benzocaine gel in children. Open Journal of Stomatology. 2011;1:84-91.

20. Rai K, Hegde AM, Jacob M, Charyulu RN. Comparative evaluation of the efficacy of lignocaine and benzocaine patches for various dental treatments in children. NUJHS. 2014;4:28-34.

21. Pozos-Guillén A, Chavarría-Bolaños D, GarrochoRangel A. Split-mouth design in Paediatric Dentistry clinical trials. Eur J Paediatr Dent. 2017;18:61-5. doi 10.23804/ejpd.2017.18.01.13.

22. Tomlinson D, von Baeyer CL, Stinson JN, Sung L. A systematic review of faces scales for the self- report of pain intensity in children. Pediatrics. 2010;126:e1168-98. doi: 10.1542/peds.2010-1609. Epub 2010 Oct 4.

23. Birnie KA, Hundert A, Lalloo C, Nguyen C, Stinson J. Recommendations for selection of self-report pain intensity measures in children and adolescents: a systematic review and quality assessment of measurement properties. Pain.2019;160:5-18.

24. Tsze DS, Hirschfeld G, von Baeyer CL, Bulloch B, Dayan PS. Clinically significant differences in acute pain measured on self report pain scales in children. Acad Emerg Med. 2015;22:415-22. doi: 10.1111/acem.12620. Epub 2015 Mar 13.

25. Clemente I. Pain in cultural and communicative context. In: McGrath P, Stevens B, Walker S, Zempsky W, editors. Oxford Textbook of Pediatric Pain. UK: Oxford University Press; 2014.p 102-10
26. Srouji R, Ratnapalan S, Schneeweiss S. Pain in Children: Assessment and Nonpharmacological Management. Int J Pediatr.2010;2010 DOI: 10.1155/2010/474838. Epub 2010 Jul 25

27. Fox A, Ayyangar R, Parten R, Haapala H, Schilling S, Kalpakjian C.Self-report of pain in young people and adults with spastic cerebral palsy: interrater reliability of the revised Face, Legs ,Activity, Cry, and Consolability (r-FLACC) scale ratings. Dev Med Child Neurol. 2019;61:69-74. doi: 10.1111/dmcn.13980.

28. Alanazi KJ, Pani S, AlGhanim N. Efficacy of external cold and a vibrating device in reducing discomfort of dental injections in children: A split mouth randomised crossover study. Eur Arch Paediatr Dent.2019 ;20:79-84. doi: 10.1007/s40368-018-0399-8.

29.Tsze DS, Dayan PS, Bulloch B, von Baeyer CL. Validation of self-report pain scales in children. Pediatrics. 2013;132:971-9.

30. Fathi A, Al-Sharabasy A. Threshold of Pain Perception to Intraoral Anesthetic Injections among Egyptian Children. Life Sci J. 2012; 9:1480-3.

31. Sharifi R, Salehian S, Sadeghi M, Mozaffari HR. Effect of Topical Anesthetics on Pain During Needle Insertion of Maxillary Infiltration Anesthesia: A Systematic Review and meta-Analysis Study. Sch Acad J Pharm. 2017;6:16-26.

32. Bagherian A, Sheikhfathollahi M. Children's behavioral pain reactions during local anesthetic injection using cotton-roll vibration method compared with routine topical anesthesia: A randomized controlled trial. Dent Res J (Isfahan). 2016;13:272-7.

33. Houzain S. Assessment of pain reaction during extraction of primary maxillary molars performed with and without palatal injection:clinical trial "master's thesis”.Alexadria, Egypt: Alexandria university;2014.

34. de Freiras GC, Pozzobon RT, Blaya DS, Moreira CH. Efficacy of Benzocaine 20\% Topical Anesthetic Compared to Placebo Prior to Administration of Local Anesthesia in the Oral Cavity: A Randomized Controlled Trial. Anesth Prog. 2015;62:46-50. doi: 10.2344/00033006-62.2.46.

35. Franz-Montan M, de Paula E, Groppo FC, Silva AL, Ranali J, Volpato MC. Liposomal delivery system for topical anaesthesia of the palatal mucosa. $\mathrm{Br} \mathrm{J}$ Oral Maxillofac Surg. 2012;50:60-4. doi: 10.1016/j.bjoms.2010.10.018.

36. Kreider KA, Stratmann RG, Milano M, Agostini FG, Munsell M. Reducing children's injection pain: Lidocaine patches versus topical benzocaine gel. Pediatr Dent. 2001;23:19-23.

37. Nakamura S, Matsuura N, Ichinohe T, A new method of topical anesthesia by using anesthetic solution in a patch. J of Endodontics.2013;39:1369-73. 